\title{
Optimization Research of cascade waste heat utilization in a hospital
}

\author{
SONG Yanli ${ }^{1, a}$ \\ ${ }^{1}$ SEP Key Laboratory of Eco-Industry, Northeastern University, Shenyang \\ asyjz_song@163.com
}

\begin{abstract}
Keywords: Waste heat ; Cascade utilization ; Hospital ; Optimization ; System
\end{abstract}
Abstract. The waste heat utilization rate of the waste heat utilization system of large-scale comprehensive hospital is analyzed, and the maximum recovery work of waste heat is obtained On the basis of the above analysis, according to the actual situation of large comprehensive hospital waste heat utilization system to simulate and analyze the process, and then establishes a calculation model of system optimization, the thermoeconomic optimization angle system, with the rate of the utilization of waste heat waste heat utilization system comparative analysis. The limiting condition of waste heat utilization system is put forward. The waste heat utilization rate analysis method for the optimization of the whole system by the heat, large comprehensive hospital waste heat utilization system is analyzed to establish optimization model of waste heat utilization system of large comprehensive hospital, the optimal solution, when the temperature, the maximum heat recovery, heat recovery rate was $77.7 \%$.

\section{Introduction}

With the improvement of living standards, energy consumption of large-scale comprehensive hospitals and other public buildings in large public buildings as grow with each passing day, the hospital of people's life, in the future the energy consumption will be faced with a severe situation not only increase. However, the energy is an indispensable element of hospital development, strengthens the energy management of the hospital, not only is the implementation of Scientific Outlook on Development, creating a green hospital, inevitable choice to alleviate the pressure on resources and the environment, but also the important measure to reduce operating costs and achieve the sustainable development of the hospital. For the energy saving and waste heat utilization of hospitals, many aspects can be involved, of which there is no in-depth study on the waste heat utilization of large-scale comprehensive hospitals. Therefore, this paper makes investigation and research.

The significance of this study is to establish the system of waste heat recovery, waste heat recovery using more reasonable rate analysis based on the large comprehensive hospital waste heat utilization system optimization, after optimization, the rate of utilization of waste heat to achieve better, and the best heat utilization scheme. For large buildings, especially in system design and practical use of waste heat utilization on the hospital to provide new ideas, put forward the direction and make use of waste heat to be further expanded, ultimately achieve energy saving goal.

Observation and analysis shows that each can provide the location of waste heat resources can be recycled waste heat, this article will be able to provide and use the location of waste heat is called waste heat utilization point. Through the actual investigation of the hospital, it is found that every hospital has more than 5 waste heat utilization points. According to the analysis results, the waste heat utilization system is established. Finally, an optimization mathematical model is established to obtain the optimal solution of the maximum waste heat utilization.

\section{Waste heat recovery rate analysis of a hospital waste heat recovery system}

For the research methods of waste heat recovery rate, after consulting a large number of documents, no reliable evaluation methods have been found. In this paper, it is suitable for the first law of thermodynamics to solve the waste heat recovery rate and analyze it because the condition parameter is temperature. First of all, the heat recovery efficiency and the waste heat recovery loss of each heat 
recovery unit are calculated. On this basis, the total residual heat of each heat recovery unit can be obtained.

The waste heat recovery rate is calculated for each part of the thermodynamic system, and the waste heat recovery loss or the waste heat recovery efficiency of each part is calculated

Tab1 Heat recovery unit 1 parameters

\begin{tabular}{ccccccccc}
\hline \multirow{2}{*}{ Type } & $\begin{array}{c}\text { Thermal } \\
\text { fluid } \\
\text { flow } \\
(\mathrm{t} / \mathrm{h})\end{array}$ & $\begin{array}{c}\text { Thermal } \\
\text { fluid } \\
\text { parameter } \\
\left({ }^{\circ} \mathrm{C}\right)\end{array}$ & $\begin{array}{c}\text { Cold } \\
\text { Fluid } \\
\text { flow } \\
(\mathrm{t} / \mathrm{h})\end{array}$ & $\begin{array}{c}\text { Cold } \\
\text { fluid } \\
\text { parameter } \\
\left({ }^{\circ} \mathrm{C}\right)\end{array}$ & $\begin{array}{c}\text { Heat } \\
\text { area } \\
\mathrm{m}^{2}\end{array}$ & $\begin{array}{c}\text { Transfer } \\
\text { coefficient } \\
\mathrm{W} /\left(\mathrm{m}^{2}{ }^{\circ} \mathrm{C}\right)\end{array}$ & $\begin{array}{c}\text { Recovery } \\
\text { Efficiency } \\
(\%)\end{array}$ & $\begin{array}{c}\text { Recovery } \\
\text { Loss } \\
(\%)\end{array}$ \\
\cline { 1 - 7 } Water & 4 & $37-24$ & 5 & $20-30$ & 8 & 2000 & 76 & 24 \\
\cline { 2 - 7 } Water & 4 & $37-24$ & 20 & $20-30$ & 16 & 2000 & 76 & 24 \\
\hline
\end{tabular}

The recovery efficiency of the waste heat and the waste heat recovery loss of the heat recovery device 1-1 are as follows:

Waste heat recovery efficiency: $\eta_{e}=\frac{E_{g}}{E_{p}}=\frac{37-24}{37-20}=\frac{13}{17}=76 \%$

Waste heat recovery loss: $\xi_{e}=1-\eta_{e}=1-76 \%=24 \%$

Tab2 Heat recovery unit 2 parameters

\begin{tabular}{|c|c|c|c|c|c|c|c|c|}
\hline Type & $\begin{array}{l}\text { Thermal } \\
\text { fluid } \\
\text { flow } \\
\text { (t/h) }\end{array}$ & $\begin{array}{l}\text { Thermal } \\
\text { fluid } \\
\text { parameter } \\
\left({ }^{\circ} \mathrm{C}\right)\end{array}$ & $\begin{array}{l}\text { Cold } \\
\text { Fluid } \\
\text { flow } \\
(\mathrm{t} / \mathrm{h})\end{array}$ & $\begin{array}{c}\text { Cold } \\
\text { fluid } \\
\text { parameter } \\
\left({ }^{\circ} \mathrm{C}\right)\end{array}$ & $\begin{array}{c}\text { Heat } \\
\text { area } \\
\mathrm{m}^{2}\end{array}$ & $\begin{array}{c}\text { Transfer } \\
\text { coefficient } \\
\mathrm{W} /\left(\mathrm{m}^{2 \circ} \mathrm{C}\right)\end{array}$ & $\begin{array}{l}\text { Recovery } \\
\text { Efficiency } \\
\quad(\%)\end{array}$ & $\begin{array}{c}\text { Recovery } \\
\text { Loss } \\
(\%)\end{array}$ \\
\hline \multirow{3}{*}{$\begin{array}{l}\text { Water } \\
\text { Water }\end{array}$} & 3 & $45-36$ & 4 & $30-37$ & 4 & 2000 & \multirow{3}{*}{60} & \multirow{3}{*}{40} \\
\hline & 4 & $45-36$ & 5 & $30-37$ & 5 & 2000 & & \\
\hline & 13 & $45-36$ & 20 & $30-37$ & 17 & 2000 & & \\
\hline
\end{tabular}

The recovery efficiency of the waste heat and the waste heat recovery loss of the heat recovery device 1-2are as follows:

Waste heat recovery efficiency: $\eta_{e}=\frac{E_{g}}{E_{p}}=\frac{37-24}{37-20}=\frac{13}{17}=76 \%$

Waste heat recovery loss: $\xi_{e}=1-\eta_{e}=1-76 \%=24 \%$

Tab3 Heat recovery unit 3parameters

\begin{tabular}{|c|c|c|c|c|c|c|c|c|}
\hline Type & $\begin{array}{l}\text { Thermal } \\
\text { fluid } \\
\text { flow } \\
\text { (t/h) }\end{array}$ & $\begin{array}{l}\text { Thermal } \\
\text { fluid } \\
\text { parameter } \\
\left({ }^{\circ} \mathrm{C}\right)\end{array}$ & $\begin{array}{l}\text { Cold } \\
\text { Fluid } \\
\text { flow } \\
(\mathrm{t} / \mathrm{h})\end{array}$ & $\begin{array}{c}\text { Cold } \\
\text { fluid } \\
\text { parameter } \\
\left({ }^{\circ} \mathrm{C}\right)\end{array}$ & $\begin{array}{c}\text { Heat } \\
\text { area } \\
\mathrm{m}^{2}\end{array}$ & $\begin{array}{c}\text { Transfer } \\
\text { coefficient } \\
\mathrm{W} /\left(\mathrm{m}^{2 \circ} \mathrm{C}\right)\end{array}$ & $\begin{array}{c}\text { Recovery } \\
\text { Efficiency } \\
\quad(\%)\end{array}$ & $\begin{array}{c}\text { Recovery } \\
\text { Loss } \\
(\%)\end{array}$ \\
\hline \multirow{3}{*}{$\begin{array}{l}\text { Water } \\
\text { Water }\end{array}$} & 0.8 & $170-40$ & 5 & $37-58$ & 3 & 2000 & \multirow{3}{*}{97} & \multirow{3}{*}{3} \\
\hline & 4 & $45-36$ & 5 & $30-37$ & 5 & 2000 & & \\
\hline & 13 & $45-36$ & 20 & $30-37$ & 17 & 2000 & & \\
\hline
\end{tabular}

The recovery efficiency of the waste heat and the waste heat recovery loss of the heat recovery device3-2 are as follows:

Waste heat recovery efficiency: $\eta_{e}=\frac{E_{g}}{E_{p}}=\frac{170-40}{170-37}=\frac{130}{133}=97 \%$

Waste heat recovery loss: $\xi_{e}=1-\eta_{e}=1-97 \%=3 \%$

A total of three sets of heat exchanger, the heat recovery and the recovery of the same location, the recovery of the same degree, so the heat exchanger is defined as heat exchanger 1 (including heat recovery heat exchanger 1-1, 1-2), 2 (including the heat recovery heat exchanger 2-1 2-2, the heat recovery, heat recovery, heat recovery 2-3) 3 (including heat exchanger, heat exchanger, 3-1 3-2 heat exchanger 3-3), the total amount of waste heat for: 


$$
Q_{1}=\frac{(37-24) \times 1000 \times 4.18 \times 20}{3600}=302 \mathrm{kw}
$$

By adding the residual heat of the three total heat recovery units, the maximum recovery work of the waste heat is obtained

$$
Q=Q_{1}+Q_{2}+Q_{3}=1265 \mathrm{kw}
$$

The waste heat recovery loss of each heat recovery unit is calculated as follows:

Heat recovery unit 1: $e_{1}=302 \times 24 \%=72.48 \mathrm{kw}$

The total heat recovery loss of the three total heat recovery units is added to the total heat recovery loss:

$$
\begin{aligned}
& e=e_{1} \times 2+e_{2} \times 3+e_{3} \times 3=463.62 \mathrm{kw} \\
& \xi_{\text {zong }}=\frac{\left(e_{1} \times 2+e_{2} \times 3+e_{3} \times 3\right)}{Q}=36.66 \%
\end{aligned}
$$

The waste heat recovery system in this hospital is used as:

$\eta_{\text {zong }}=63.34 \%$

Because some of the waste heat recovery in this process is relatively simple, and the system research is not integrated, it is necessary to optimize the system design.

\section{Analysis and optimization method of waste heat utilization system in large scale general hospital}

In this paper, the following 2 steps are used to analyze the characteristics of the waste heat utili zation system in a large comprehensive hospital:

1) Based on energy conservation, mass continuity and pressure balance equations, all unknown thermodynamic parameters of the whole system are calculated according to the design requirements and known design variables.

2) Large scale comprehensive hospital waste heat utilization system is mainly composed of boil er, heat recovery unit 1 , heat recovery unit 2 , heat recovery device 3 , four components, so the system components design is also composed of four parts.

Design of heat recovery unit: the design of heat recovery unit is more complicated, but the relat ed literature can be simplified by using some approximate simple treatment methods.

1. range of design variables.

$$
\left[\begin{array}{c}
32 \\
20 \\
37 \\
45 \\
180
\end{array}\right] \leq\left[\begin{array}{c}
X_{1} \\
X_{2} \\
X_{3} \\
X_{4} \\
X_{5}
\end{array}\right] \leq\left[\begin{array}{c}
37 \\
37 \\
45 \\
180 \\
\infty
\end{array}\right]
$$

1) To ensure that the temperature of the boiler is $108^{\circ} \mathrm{C}$, the temperature of domestic sewage is below $40^{\circ} \mathrm{C}$, the temperature of domestic water is $65^{\circ} \mathrm{C}$, the temperature of domestic cold water is $20^{\circ} \mathrm{C}$, and the temperature of softened water is $20^{\circ} \mathrm{C}$.

2) Optimization calculation method selection and program block diagram.

Since the established objective function and most of the constraint functions are nonlinear functions of design variables, the optimal design of the waste heat utilization system in large-scale comprehensive hospitals is a nonlinear programming problem.

In addition, there is no direct analytic expression between the objective function and the design variables. It is very difficult to obtain the partial derivatives of the objective function, so the complex method can be chosen to solve the problem. The optimized design block diagram of the waste heat recovery system is shown in the figure. By optimizing the model, MATLAB software is used to obtain the temperature $\mathrm{t}_{1}=22^{\circ} \mathrm{C}, \mathrm{t}_{2}=33^{\circ} \mathrm{C}, \mathrm{t}_{3}=42^{\circ} \mathrm{C}, \mathrm{t}_{4}=180^{\circ} \mathrm{C}$, The maximum recovery rate of waste heat 
is obtained, and the recovery rate of waste heat is $77.7 \%$.

\section{Conclusion}

In this paper, as a preliminary exploration of large comprehensive hospital waste heat utilization, primarily for domestic energy and waste heat utilization and to do a simple understanding of energy transformation in public buildings, a large number of documents, find the existing problems and the solving method and related problems. Although different methods of domestic researchers on the use of waste heat of the public buildings have carried out a lot of work, but whether starting from the development of the industry or the perspective of technological progress, the use of large public buildings for comprehensive waste heat rate is not high, China's large-scale comprehensive hospital waste heat utilization system of field remains to be further studied. Compared with the international advanced level, there are still some backward, especially in a variety of theories that are active today, mathematical calculation technology into large comprehensive hospital waste heat utilization system method is not universal. There are few large-scale public buildings which form the waste heat utilization system. Therefore, all the researchers who are engaged in the hospital waste heat utilization system still need to make great efforts and exploration. The significance of this study is to use a large comprehensive hospital more reasonable utilization of residual heat and system, and then the large comprehensive hospital waste heat utilization system to optimize the analysis, make better use of waste heat utilization system after optimization of heat energy, which is more than the actual hospital heat utilization system provides new ideas of design, and have a certain theoretical guidance, make use of waste heat is more reasonable.

\section{References}

[1]Min Li,Bingxiong Zhao. Analytical thermal efficiency of medium-low temperature organic Rankine cycles derived from entropy-generation analysis[J].Energy,2016

[2] Jiacheng Ma, Liuchen Liu, Tong Zhu, Tao Zhang. Cascade utilization of exhaust gas and jacket water waste heat from an Internal Combustion Engine by a single loop Organic Rankine Cycle system [J].Applied Thermal Engineering, 2016

[3]Carlos Rubio-Maya,Edgar Pastor Martínez. Techno-economic assessment for the integration into amulti-product plant based on cascadeutilization of geothermal energy[J].Applied Thermal Engineering, 2016, 108:.

[4]Jiang Qin, Kunlin Cheng, Silong Zhang, Duo Zhang, Wen Bao, Jiecai Han. Analysis of energy cascadeutilization in a chemically recuperated scram jet within direct combustion[J].Energy, 2016,:

[5]Xiaoqu Han, Junjie Yan, Sotirios Karellas, Ming Liu, Emmanuel Kakaras, Feng Xiao. Wate rextraction from high moisture lignite by means of efficient integration of waste heat and water recovery technologies with flue gaspre-drying system[J].Applied Thermal Engineering, 2017,110:.

[6]Hossam A. Gabbar, C. A. Barry Stoute, Derek Steele, Cole Simkin, Thomas Sleeman, David Newell, Dominique Paterson, Emmanuel Boafo. Evaluation and Optimization of Thermoelectric Generator Network for Waste Heat Utilizationin Nuclear Power Plants and Non-Nuclear Energy Applications [J].Annals of Nuclear Energy,2016,:.

[7]Shifei Zhao, Xiaoze Du, Zhihua Ge, Yongping Yang. Cascade Utilization of Flue Gas Waste Heatin Combined Heat and Power System with high Back-pressure (CHP-HBP) [J].Energy Procedia, 2016, 104:

[8]Paweł Ziółkowski, Tomasz Kowalczyk, Sebastian Kornet, Janusz Badur. On low-grade waste heat utilization from a supercritical steam power plant using an ORC-bottoming cycle coupled with two sources of heat [J].Energy Conversion and Management, 2017,: 
ATLANTIS
PRESS 